\title{
Trends of Convective and Stratiform Precipitation in the Czech Republic, 1982-2010
}

\author{
Zuzana Rulfová ${ }^{1,2,3}$ and Jan Kyselý ${ }^{1,2}$ \\ ${ }^{1}$ Technical University of Liberec, Studentská 1402/2, 46117 Liberec, Czech Republic \\ ${ }^{2}$ Institute of Atmospheric Physics AS CR, Boční II 1401, 14131 Prague 4, Czech Republic \\ ${ }^{3}$ Faculty of Mathematics and Physics, Charles University, V Holešovičkách 2, 18000 Prague 8, Czech Republic
}

Correspondence should be addressed to Zuzana Rulfová; rulfova@ufa.cas.cz

Received 6 November 2013; Accepted 20 January 2014; Published 2 March 2014

Academic Editor: Eduardo García-Ortega

Copyright (C) 2014 Z. Rulfová and J. Kyselý. This is an open access article distributed under the Creative Commons Attribution License, which permits unrestricted use, distribution, and reproduction in any medium, provided the original work is properly cited.

\begin{abstract}
The study examines trends in characteristics of convective and stratiform precipitation in the Czech Republic over 1982-2010. The spatially averaged trends in convective precipitation are rising for indices of mean precipitation, and the increases are significant in all seasons except for winter. For extremes, the trends are spatially much more variable and insignificant, but increases tend to prevail as well. The trends in convective precipitation are larger in the western part of the country where Atlantic influences are stronger. For characteristics of stratiform precipitation, the trends are usually smaller compared to those of convective precipitation, but increases prevail too. They are significant in autumn, especially for extremes, and larger in the eastern part of the country where Mediterranean cyclones play more important role. The trends in convective precipitation tend to be more pronounced at lowland than higher-elevated stations while an opposite pattern prevails for stratiform precipitation. The results suggest that in spring and summer, when convective precipitation represents an important fraction of the total amounts in central Europe (around 30\% and $50 \%$, respectively), the observed increases in total precipitation are mainly due to increases in convective precipitation. In autumn, increases in both convective and stratiform precipitation are important, and the trends are weakest and least pronounced in winter.
\end{abstract}

\section{Introduction}

Significant trends in characteristics of atmospheric precipitation were observed in Europe in recent decades. Predominantly increasing trends were reported in winter (e.g., [1-3]) except for the Mediterranean [4-6]. In spring and summer, trends of extreme and mean precipitation are spatially less coherent. In spring, decreasing trends were observed in the southern Iberian Peninsula $[6,7]$, in Italy [5], and in the Czech Republic [3] while increasing trends were observed in Germany and the United Kingdom (e.g., [2, 8]). In summer, decreasing trends were found over northern part of Europe while increasing trends over central and western part of Europe (e.g., [9]) except for Germany (e.g., [10]), Poland $[11,12]$, and the Iberian Peninsula (e.g., [13]). In autumn, increasing trends of extreme precipitation prevail in many European regions except in north-eastern Germany (e.g., $[2,3,8,14])$.
Little attention has been paid to the question whether these trends are related to changes in the proportion of precipitation falling from convective and stratiform clouds. The probable reason is the lack of long-term series of precipitation data disaggregated according to their origin into convective and stratiform. Although the concepts of stratiform and convective precipitation are simplified and there is no clear borderline between the two (e.g., in the case of embedded convection within large-scale stratiform clouds and related spatial patterns of precipitation), these two types are associated with different precipitation growth mechanisms and both play important roles in precipitation amounts falling during warm half-year in central Europe.

In recent years, several studies have aimed at discriminating convective and stratiform precipitation on the basis of different instruments and techniques. Many methods originate from studies of ground-based observations, but more recent methods devised for disaggregating rainfall often 
use data from radar and satellite measurements (e.g., [15, 16]). Although methods based on radar and satellite data provide useful tools for such meteorological applications as forecasting precipitation and analysing development of precipitation systems (e.g., [17]), they are not applicable to climatological studies because of the short records of available data.

Ruiz-Leo et al. [18] presented a relatively new method based on 6-hour precipitation amounts from stations (standard synoptic data) that provides the opportunity to acquire long-time series of convective and stratiform precipitation for analyses of changes in precipitation regimes. They examined trends of convective and stratiform precipitation for the Spanish Mediterranean coast over 1998-2008 and found that the increasing trends of total precipitation were due to trends in convective precipitation in autumn while stratiform precipitation in spring. In winter and summer, neither convective nor stratiform precipitation had a prevailing role in trends of total precipitation.

In this study, we analyse trends of convective and stratiform precipitation in the Czech Republic (central Europe) over 1982-2010. Time series of convective and stratiform precipitation are obtained using a recently proposed algorithm for disaggregation of precipitation based on SYNOP reports (surface synoptic observations) at weather stations [19]. Our approach is based on the same type of data as the method used in [18], but we relax the simplifying assumption that heavy precipitation is of convective origin only. The algorithm is based on several criteria, allowing also for disaggregation of heavy precipitation into predominantly convective and stratiform.

The paper is structured as follows. After a short description of the data and precipitation patterns in the Czech Republic in Section 2, the algorithm for disaggregation of precipitation is presented in Section 3, together with the methodology applied to trend analysis. The results of the trend analysis of convective and stratiform precipitation are reported in Section 4. Section 5 contains discussion of the results, and conclusions follow in Section 6.

\section{Data and Area under Study}

2.1. SYNOP Data. The precipitation data originate from SYNOP reports at 11 stations operated by the Czech Hydrometeorological Institute (CHMI). Geographical positions of the examined stations are depicted in Figure 1. The altitudes of the stations range from 241 to $1322 \mathrm{~m}$ a.s.l., and the stations cover different climatological regions from lowlands to mountains. The observations span from 1982 to 2010. The dataset includes 6-hour precipitation amounts, codes of present and past weather (weather state) during the 6hour interval, and hourly data on cloud cover, cloud type, air pressure, and temperature.

The quality of the data was thoroughly checked to uncover possible errors and suspicious 6-hour precipitation records. Some missing and incorrect precipitation readings were filled in by comparing the SYNOP data with daily totals from climatological measurements (aggregated 24-hour amounts).
The majority of stations have a negligible percentage of missing 6-hour precipitation data (less than $0.1 \%$ ). Exceptions were stations 11698, with 4 months of missing data (JanuaryApril 1989), and 11406, with 3 months of missing data (October-December 1993). The affected seasons (winter and spring 1989, autumn and winter 1993) were omitted from the analysis at the given stations.

2.2. Precipitation Patterns in the Czech Republic. Precipitation in the Czech Republic has large spatial and temporal variability. The annual cycle has a single maximum in June and July and minimum in January and February [20]. Stratiform precipitation predominates in all seasons except summer, at which time the proportion of convective precipitation increases and leads to slightly higher amounts of convective than stratiform origin at most stations [19]. Daily precipitation amounts are greater in the warm half of the year while the number of days with precipitation is greater in the cold half of the year [20].

Spatial variability of precipitation is caused by the influence of the large-scale atmospheric circulation which can be modified by local-scale parameters such as orography, wind exposure, precipitation shadow, and direction of mountain range. While an inflow of moist maritime air from the north Atlantic strongly influences the western part of the Czech Republic, an inflow of warm, moist air from the Mediterranean plays a more pronounced role in the eastern part of the country (e.g., [21]).

\section{Methods}

3.1. Algorithm for Disaggregation of Precipitation. The time series of convective and stratiform precipitation were obtained using the algorithm proposed and evaluated in detail in [19]. As convective and stratiform precipitation fall from different clouds (convective from $\mathrm{Cb}$ and $\mathrm{Cu}$ while stratiform from Ns, Sc, St, and As) and they are characterized by different types of weather events, the algorithm disaggregates 6-hour precipitation amounts into predominantly convective and stratiform on the basis of weather state (the main criterion) and cloud type (the secondary criterion). Showers and thunderstorms are the main groups of weather states typical for convective precipitation while drizzle, rain, and snow (the latter two not in the form of showers) are typical for stratiform precipitation. Details on the weather state coding are given in [19].

The algorithm is structured into three main steps. First, it searches for nonzero 6-hour precipitation amounts and reads all hourly data for weather state and cloud type during the 6-hour period. Second, it disaggregates precipitation into convective and stratiform using the main criterion. If the precipitation amount is classified as mixed/unresolved at this stage (occurrence of codes of weather state associated with both convective and stratiform precipitation within the 6hour interval or the data on weather state is missing), the secondary criterion based on the cloud type is used. This leads to additional disaggregation. Finally, time series of convective, stratiform, and mixed/unresolved 6-hour precipitation 


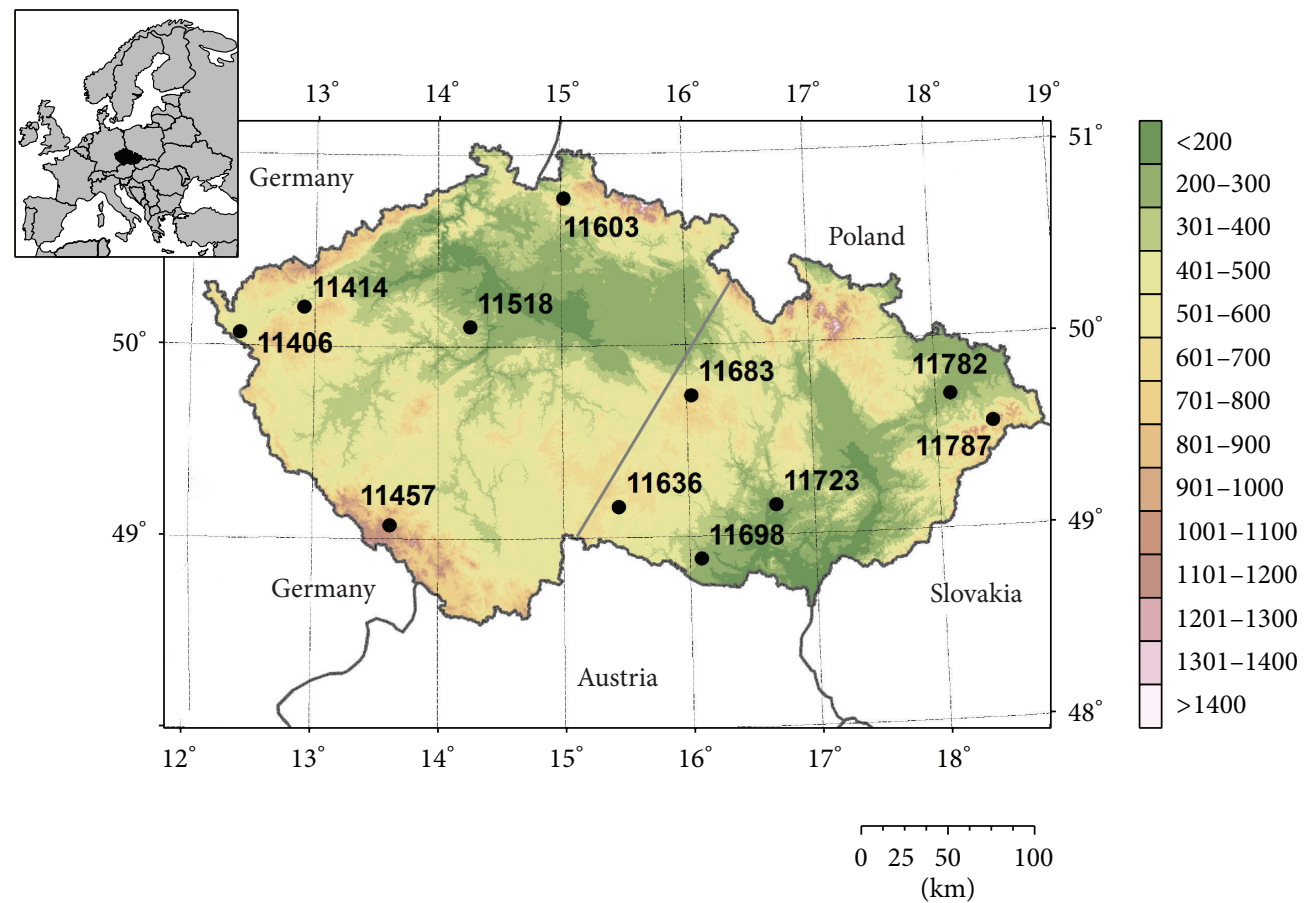

FIGURE 1: Area under study and locations of weather stations. The grey line shows a borderline between the western and eastern parts of the Czech Republic.

amounts are created. The final algorithm was selected after a number of tests, described in detail in [19]. It disaggregates about $95 \%$ of 6 -hour precipitation amounts and performs better for moderate to heavy than light precipitation. The remaining small percentage of mixed/unresolved precipitation amounts (around 5\%) does not show significant trends over time and was omitted from the analysis.

3.2. Characteristics of Precipitation. For the trend analysis, four variables and indices were selected to provide information on basic climatological characteristics of convective and stratiform precipitation (seasonal amount, the number of wet days) and extremes (maximum seasonal 6-hour and 1day precipitation amounts). According to [9], a wet day was defined as a day with (convective or stratiform) precipitation above $1.0 \mathrm{~mm}$. The acronyms used for individual characteristics are listed in Table 1.

The indices of precipitation were calculated seasonally. The seasons analysed were spring (MAM, March-April-May), summer (JJA, June-July-August), autumn (SON, SeptemberOctober-November), and winter (DJF, December-JanuaryFebruary).

3.3. Trend Estimation. Trends of precipitation indices were estimated using two methods. First, the trend magnitudes were estimated parametrically by the least-squares regression (e.g., [22]) and the statistical significance of the trends was computed by the bootstrap method (e.g., $[23,24])$. The bootstrap is a type of a Monte Carlo method which is based on resampling with replacement from the data to create
TABLE 1: Acronyms used for precipitation characteristics.

\begin{tabular}{lc}
\hline Acronym & Description \\
\hline Amount & Seasonal precipitation total \\
Days & Number of wet days \\
R6h & Maximum seasonal 6-hour precipitation amount \\
R1D & Maximum seasonal 1-day precipitation amount \\
\hline
\end{tabular}

bootstrap samples. For computing the confidence interval, we used 1,000 bootstrap samples.

Second, the nonparametric Sen's estimator of slope, also known as the "median of pair-wise slopes" or Theil-Sen estimator [3, 25], was computed. The statistical significance of the trends was evaluated using the Mann-Kendall test $[26,27]$. This is a rank-based test that is robust to outliers and does not depend on the assumption of Gaussian distribution of residuals.

The statistical significance of precipitation trends is usually lower compared with other climate elements due to large spatial and temporal variability of precipitation. Therefore, we evaluate the results at lower significance levels of $p=$ 0.1 and $p=0.2$. All trend magnitudes were expressed as relative changes of the examined characteristics in $\% / 10$ years, allowing easier comparison among the indices and seasons.

\section{Results}

Since precipitation has large random spatial variability and the study area is relatively small, we evaluate time series 
TABLE 2: Trend magnitudes (expressed as relative change of the examined characteristics in $\% / 10$ years) of average precipitation characteristics from all stations over 1982-2010. ${ }^{*}\left({ }^{* *}\right)$ denotes trend significant at the $0.2(0.1)$ level.

\begin{tabular}{|c|c|c|c|c|c|c|}
\hline \multirow{2}{*}{ Characteristics } & \multicolumn{2}{|c|}{ Convective } & \multicolumn{2}{|c|}{ Stratiform } & \multicolumn{2}{|c|}{ Total } \\
\hline & Lin. reg. & Sen & Lin. reg. & Sen & Lin. reg. & Sen \\
\hline \multicolumn{7}{|l|}{ Spring } \\
\hline Amount & $9.2^{* *}$ & $8.0^{*}$ & 0.0 & -0.7 & 5.6 & $3.9^{*}$ \\
\hline Days & $14.7^{* *}$ & $14.0^{* *}$ & -3.1 & -3.7 & 3.0 & 1.5 \\
\hline R6h & -5.7 & -4.1 & 3.9 & 5.5 & -0.2 & -0.7 \\
\hline R1D & -3.8 & -4.1 & 2.9 & 4.1 & 2.5 & 1.4 \\
\hline \multicolumn{7}{|l|}{ Summer } \\
\hline Amount & $7.5^{* *}$ & 4.4 & 3.0 & 2.7 & $6.9^{*}$ & 5.2 \\
\hline Days & $5.3^{*}$ & 4.6 & -4.1 & -5.2 & 1.6 & 1.4 \\
\hline R6h & 0.5 & 0.7 & 1.3 & -2.9 & 1.9 & -1.6 \\
\hline R1D & 2.2 & 2.2 & 4.9 & 2.5 & $6.6^{*}$ & 2.8 \\
\hline \multicolumn{7}{|l|}{ Autumn } \\
\hline Amount & $14.7^{* *}$ & $15.8^{* *}$ & $9.7^{*}$ & $10.7^{* *}$ & $11.9^{* *}$ & $11.5^{* *}$ \\
\hline Days & $23.0^{* *}$ & $21.7^{* *}$ & 3.2 & 4.4 & $6.9^{*}$ & $5.7^{*}$ \\
\hline R6h & 1.3 & 2.2 & $9.3^{*}$ & $12.6^{* *}$ & $8.6^{*}$ & $10.4^{*}$ \\
\hline R1D & 0.0 & 0.2 & $14.6^{* *}$ & $15.2^{* *}$ & $12.9^{* *}$ & $11.6^{* *}$ \\
\hline \multicolumn{7}{|l|}{ Winter } \\
\hline Amount & 1.6 & 1.4 & -2.2 & 0.5 & -1.1 & 2.2 \\
\hline Days & -2.0 & -1.7 & -4.2 & -2.2 & -2.7 & -3.3 \\
\hline R6h & 5.9 & -2.3 & 2.1 & 0.9 & 2.3 & 1.8 \\
\hline R1D & 3.4 & -1.4 & 2.5 & 1.5 & 2.2 & 1.3 \\
\hline
\end{tabular}

TABLE 3: Trend magnitudes (expressed as relative change of the examined characteristics in \%/10 years, from linear regression) of average precipitation characteristics over 1982-2010 for the western and the eastern part of the Czech Republic. ${ }^{*}\left({ }^{* *}\right)$ denotes trend significant at the 0.2 (0.1) level.

\begin{tabular}{|c|c|c|c|c|c|c|}
\hline \multirow{2}{*}{ Characteristics } & \multicolumn{2}{|c|}{ Convective } & \multicolumn{2}{|c|}{ Stratiform } & \multicolumn{2}{|c|}{ Total } \\
\hline & West & East & West & East & West & East \\
\hline \multicolumn{7}{|l|}{ Spring } \\
\hline Amount & $10.1^{* *}$ & $8.6^{*}$ & -5.9 & $4.9^{*}$ & 3.1 & $7.7^{* *}$ \\
\hline Days & $15.1^{* *}$ & $14.4^{* *}$ & $-5.3^{*}$ & -1.4 & 2.7 & $3.3^{*}$ \\
\hline R6h & $-8.1^{* *}$ & -3.5 & 1.9 & $5.7^{*}$ & $-2.9^{*}$ & 2.2 \\
\hline R1D & -2.7 & -4.6 & $-5.7^{*}$ & $10.0^{* *}$ & -4.1 & $8.0^{* *}$ \\
\hline \multicolumn{7}{|l|}{ Summer } \\
\hline Amount & $7.9^{* *}$ & $7.1^{* *}$ & 3.7 & 2.5 & $7.7^{* *}$ & $6.3^{*}$ \\
\hline Days & $5.9^{* *}$ & $4.9^{* *}$ & $-5.0^{*}$ & -3.4 & 1.8 & 1.5 \\
\hline R6h & 0.5 & 0.4 & 4.3 & -1.2 & 1.8 & 2.0 \\
\hline R1D & 1.5 & 2.8 & 6.3 & 3.7 & $5.8^{*}$ & $7.3^{*}$ \\
\hline \multicolumn{7}{|l|}{ Autumn } \\
\hline Amount & $19.2^{* *}$ & $10.9^{*}$ & $7.2^{*}$ & $11.7^{* *}$ & $11.0^{* *}$ & $12.6^{* *}$ \\
\hline Days & $27.8^{* *}$ & $19.1^{* *}$ & 2.0 & $4.2^{*}$ & $7.1^{* *}$ & $6.7^{* *}$ \\
\hline R6h & 5.0 & -1.9 & 2.2 & $15.1^{* *}$ & 2.2 & $13.9^{* *}$ \\
\hline R1D & 4.5 & -4.0 & $8.1^{* *}$ & $19.9^{* *}$ & $7.1^{* *}$ & $17.7^{* *}$ \\
\hline \multicolumn{7}{|l|}{ Winter } \\
\hline Amount & 5.7 & -1.9 & $-6.0^{*}$ & 1.0 & -4.5 & 1.9 \\
\hline Days & -1.0 & -2.9 & $-5.7^{* *}$ & -3.0 & $-4.2^{*}$ & -1.4 \\
\hline R6h & $13.2^{*}$ & -0.2 & 1.3 & 2.8 & 2.6 & 2.1 \\
\hline R1D & 10.1 & -2.2 & -1.2 & $5.7^{*}$ & -1.2 & $5.2^{*}$ \\
\hline
\end{tabular}




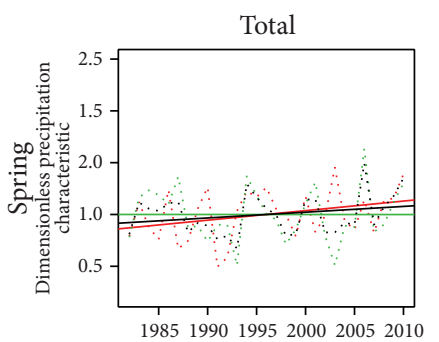

Year

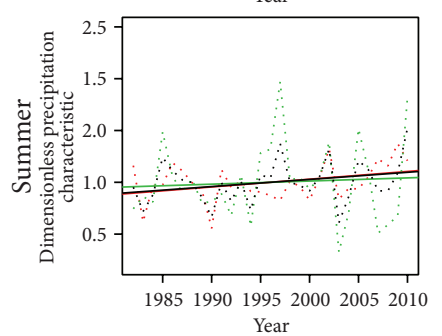

Year

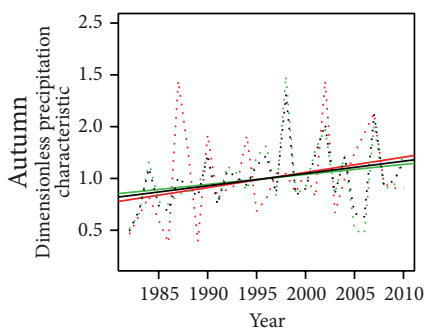

Year

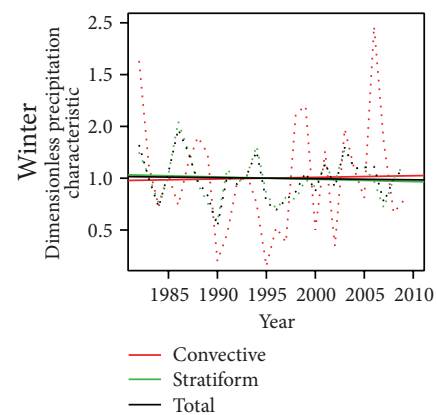

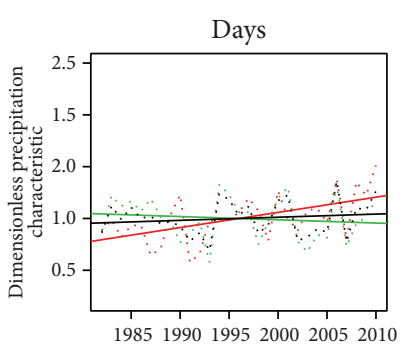

Year

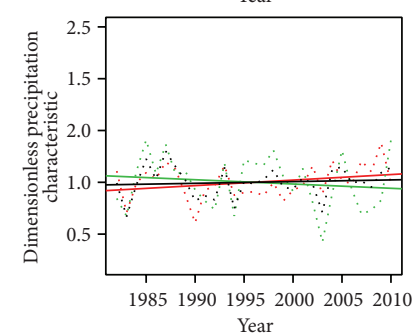

Year
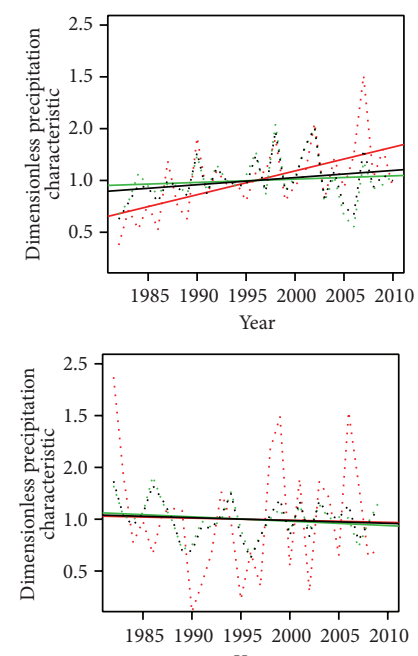

Year

- Convective

- Stratiform



Year

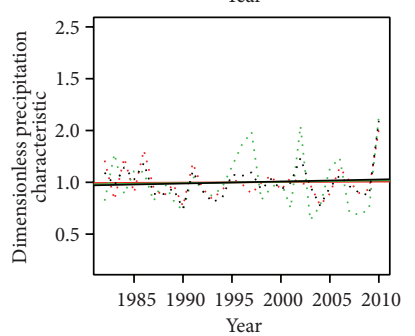

Year

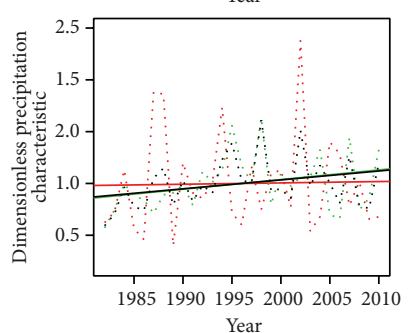

Year

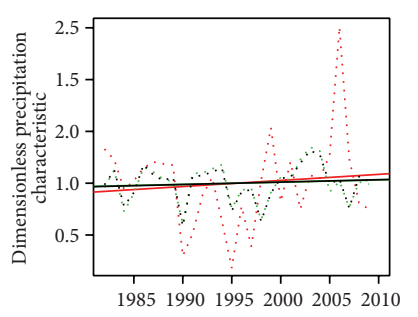

Year

- Convective

- Total

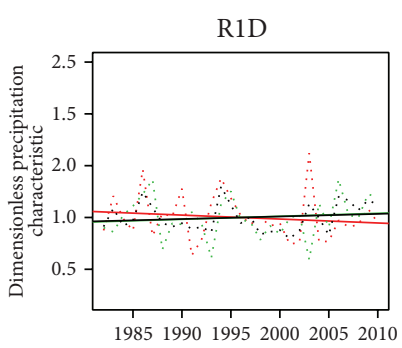

Year

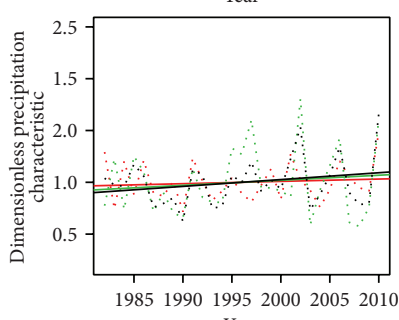

Year
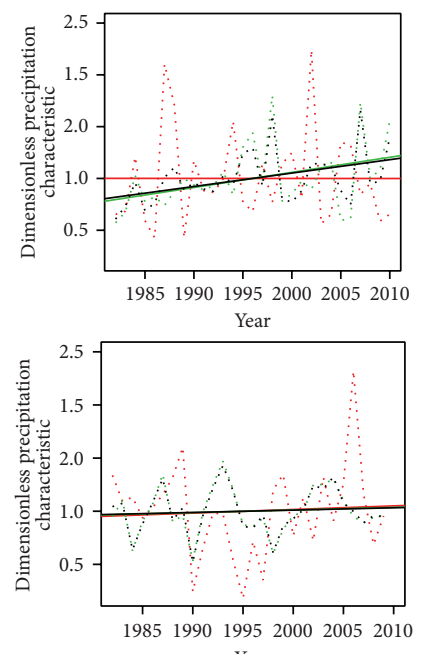

Year

_ Convective

- Total

FIGURE 2: Time series and trend magnitudes obtained by the linear regression for convective, stratiform, and total precipitation characteristics averaged over 11 stations in the Czech Republic.

obtained by averaging data from (a) all stations and (b) stations in the western and eastern parts of the Czech Republic (Figure 1). Analogous division was applied by Kyselý [3] who reported the cutoff between the western and eastern parts of the Czech Republic in trends of precipitation characteristics, which may be linked to meteorological factors, namely, differences in the roles of Atlantic and Mediterranean influences. Herein, the averages are calculated from scaled stations' data in order to give the same weight to all stations (notwithstanding the observed precipitation amounts and the number of wet days, which are larger at higher-elevated stations). The characteristics at individual stations were first divided by their mean values over the studied period and then these scaled (dimensionless) data were averaged over the stations.

The trends in spatially averaged characteristics and their statistical significance are shown in Table 2 for all stations and in Table 3 for the western and eastern parts of the Czech Republic. Time series of the spatially averaged characteristics are plotted in Figure 2, and dependence of the trend magnitudes on altitude is depicted in Figure 3. All figures and the description of results are based on the linear regression because results obtained by the parametric (least-squares regression) and nonparametric (Sen's estimator) trend estimation are similar (Table 2). Particularly, we did not find a general tendency of the parametric estimate to be greater (in absolute value) than the nonparametric estimate (cf. [28]).

4.1. Convective Precipitation. Trends of spatially averaged climatological characteristics of convective precipitation (the total amount and the number of wet days) are increasing and statistically significant in all seasons except winter (when the proportion of convective precipitation is very low; Table 2 and Figure 2). The increasing trends are higher in the western 

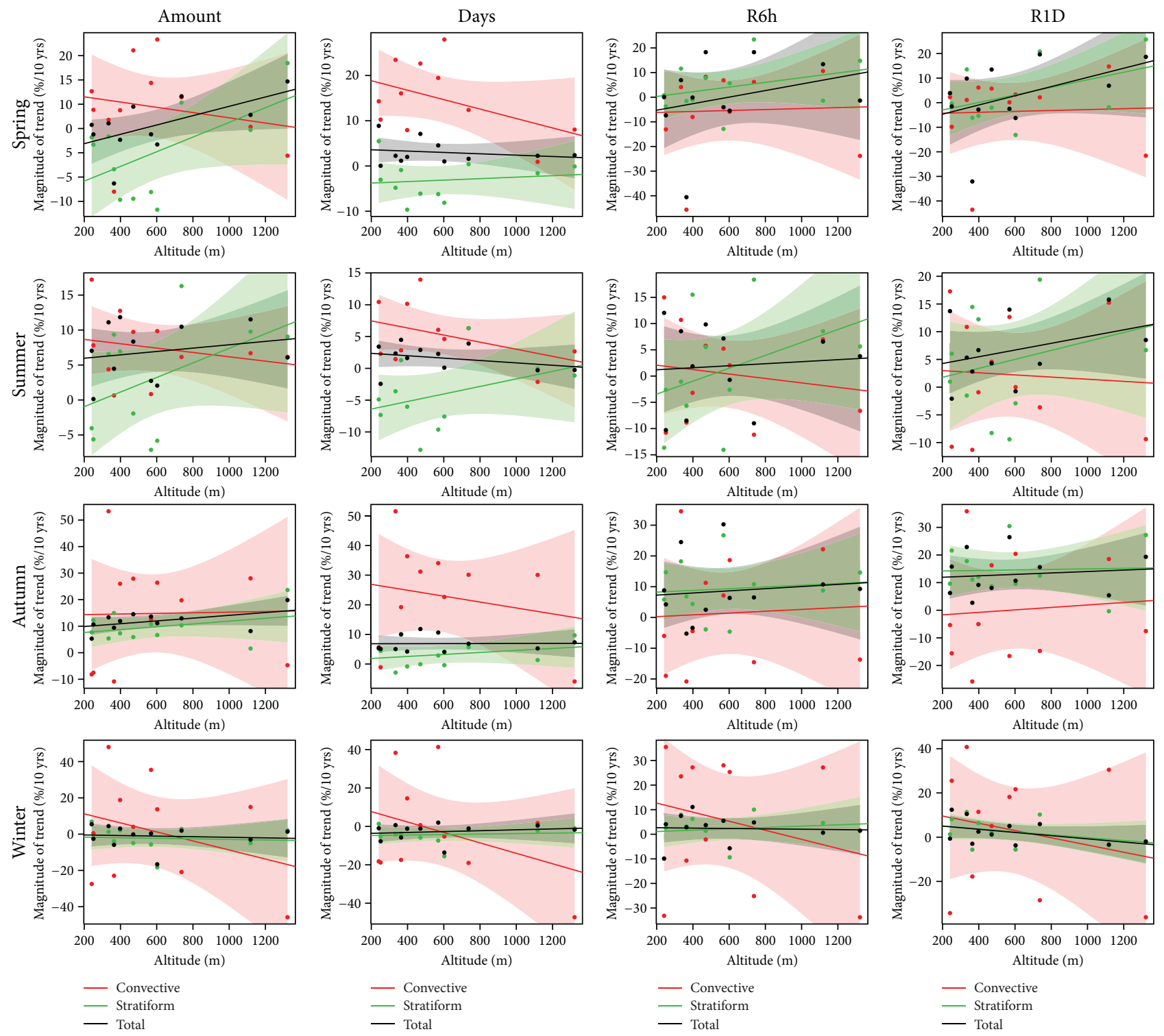

FIgure 3: Dependence between trend magnitudes and altitude for characteristics of convective, stratiform, and total precipitation. Trends estimated by the linear regression and their $95 \%$ confidence bounds are plotted.

than eastern part of the Czech Republic in all seasons (Table 3, Figure 4). Spatially averaged extreme precipitation indices of convective precipitation (seasonal maxima of 6-hour and 1-day precipitation, $\mathrm{R} 6 \mathrm{~h}$, and R1D) increase in all seasons except spring but the trends are smaller and insignificant. The trends of extreme precipitation tend to have opposite signs in autumn and winter in the western (positive) and eastern (negative) part of the country (Table 3, Figure 5). The climatological characteristics of convective precipitation increase faster in lowlands than in highlands in all seasons while for extremes such pattern is found only in summer and winter (Figure 3).

4.2. Stratiform Precipitation. The trends in characteristics of stratiform precipitation are usually smaller compared to those of convective precipitation (Table 2, Figure 2). For spatially averaged indices, increasing trends prevail as well. The largest and statistically significant trends are found in autumn, particularly for extremes. The tendency to increases is more pronounced in the eastern part of the Czech Republic in all seasons except for summer (Table 3, Figures 4 and 5). The trends of stratiform precipitation tend to be of opposite signs in the western (negative) and eastern (positive) part of the country in winter and spring, which leads to very small trends for the country as a whole. By contrast to convective precipitation, stratiform precipitation has usually more pronounced positive trends in highlands (Figure 3). Differences between lowlands and highlands are larger in spring and summer.

4.3. Total Precipitation. Increasing trends of total precipitation prevail in all seasons except winter (Table 2, Figures 2, 

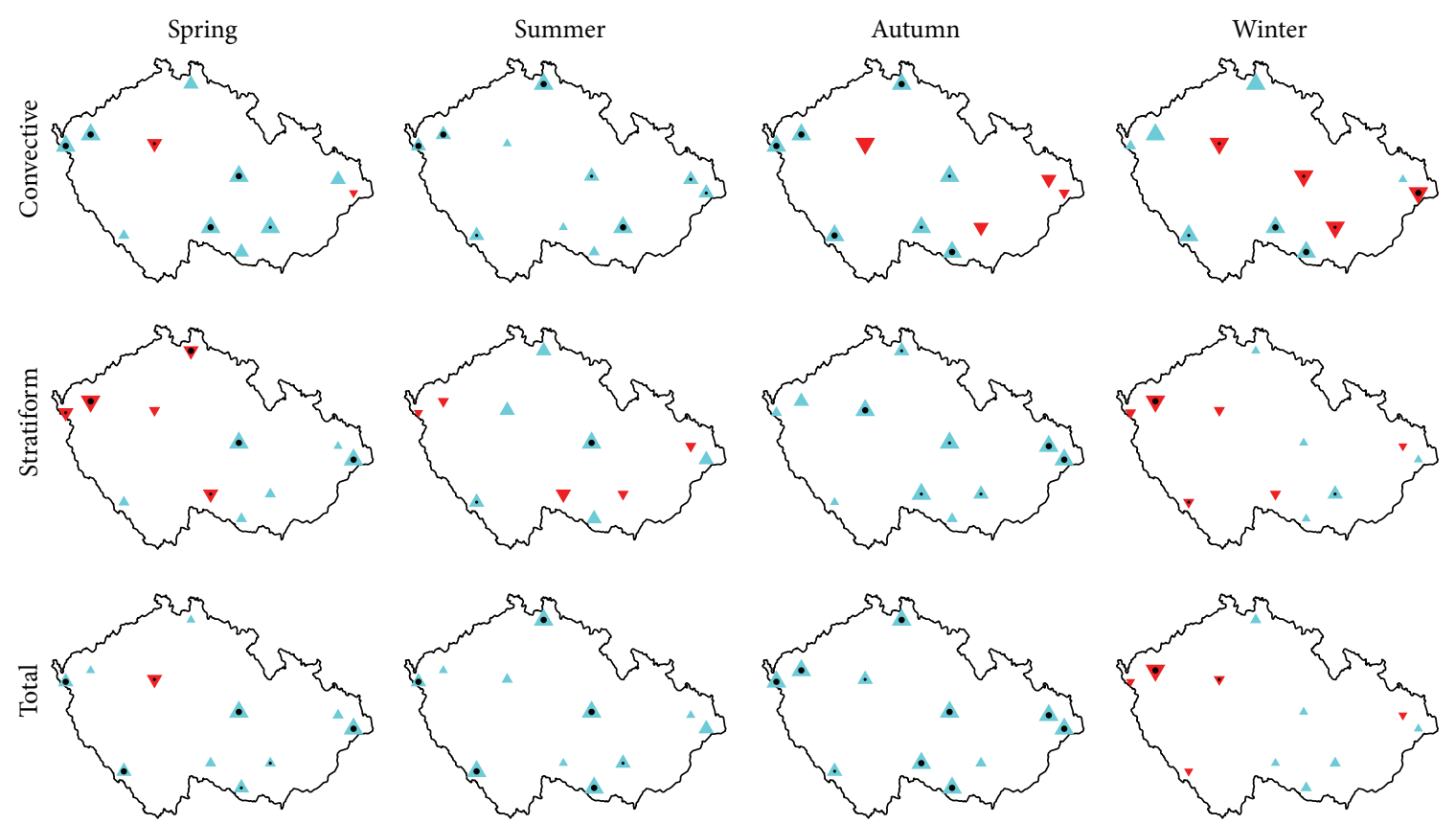

$$
\begin{array}{ll}
\text { Trend }(\% / 10 \mathrm{yrs}) & \\
\nabla<-10 & =0 \\
\nabla-10--6 & \Delta 0-3 \\
\nabla-6--3 & \Delta 3-6 \\
\nabla-3-0 & \Delta 6-10
\end{array}
$$

$$
\begin{aligned}
& \triangle>10 \\
& \text { - } p=0.2 \\
& \text { - } p=0.1
\end{aligned}
$$

FIGURE 4: Trends in seasonal amounts of convective, stratiform, and total precipitation computed by the linear regression. Trend magnitudes are expressed as relative changes of the examined characteristics in \%/10 years over 1982-2010.

4, and 5). The largest and statistically significant trends are found in autumn, which corresponds with increasing trends of both convective and stratiform precipitation. The trends of total precipitation are by far weakest in winter, when also trends of convective and stratiform precipitation are rarely significant. In spring and summer, some characteristics of convective precipitation increase while of stratiform precipitation decrease and vice versa. These counterbalancing trends of convective and stratiform precipitation lead to relatively small trends of total precipitation. The trend magnitudes of total precipitation depend on altitude similarly as those of stratiform precipitation in all seasons except summer (Figure 3), when the role of convective precipitation is largest.

The ratio between convective and stratiform precipitation increases in all seasons, especially in summer (Figure 6). It is particularly noteworthy that the four highest values over 1982-2010 occurred in the last 8 years, and the dominance of convective precipitation was greatest in the 2003 spring and summer that were characterized by severe heat waves in Europe and large precipitation deficits (e.g., [29-32]). Our results show that the deficits over central Europe were mainly due to the lack of stratiform precipitation (cf. also Figure 2).

\section{Discussion}

In all seasons in which convective precipitation represents an important part of total amounts (spring, summer, and autumn), convective precipitation increases (in averaged precipitation characteristics from all stations) more than stratiform for seasonal precipitation amounts as well as the number of wet days. Our results contrast with those reported by Ruiz-Leo et al. [18], who found steeper (positive) trends for stratiform than convective precipitation in the eastern Spanish coast. They, however, had examined not only a different area but also a much shorter time period (19982008) and used a different algorithm for disaggregating precipitation, as reported above. Our algorithm is based on different criteria, allowing also for disaggregation of heavy precipitation into predominantly convective and stratiform [19], while Ruiz-Leo et al. [18] considered heavy precipitation to be of convective origin only. Their approach was reasonable for the specific study area (north-eastern coast of Spain) but it is not generally applicable in other regions.

Mean convective precipitation increases significantly in all seasons except winter while heavy precipitation decreases in spring or has small insignificant trends in summer and autumn. Our results are in agreement with [33,34], where climatological characteristics and trends of thunderstorms over Poland were studied and increasing trends of days with light thunderstorm at the end of the 20th century while decreasing or no clear trends of days with heavy thunderstorm were reported.

There is an ongoing discussion concerning possible changes in precipitation rates and relative contributions 

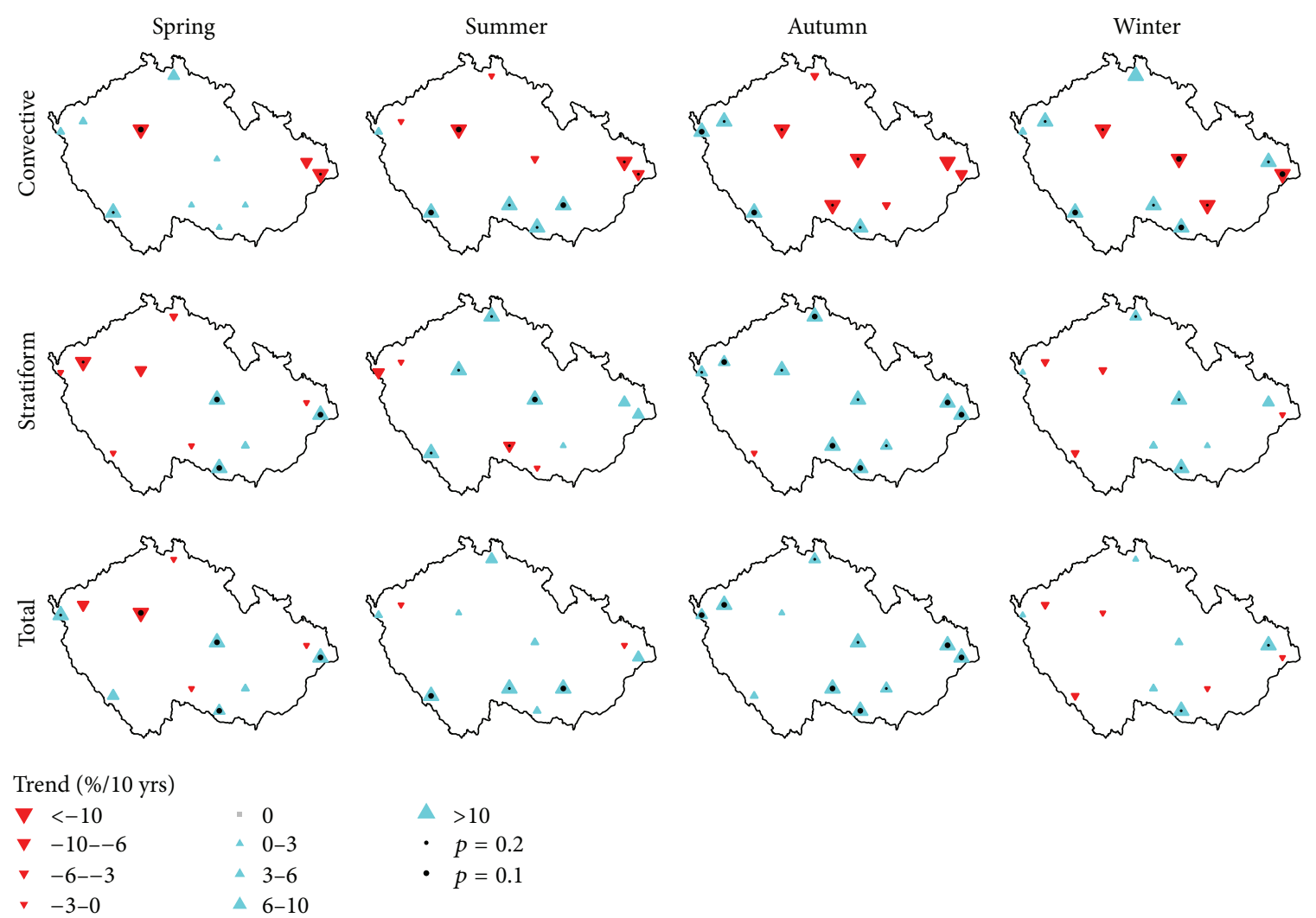

FIGURE 5: Same as in Figure 4 but for maximum seasonal 1-day precipitation amount (R1D).

of convective and stratiform precipitation with increasing surface temperatures (e.g., $[35,36])$. Increasing proportion of convective precipitation, found in all seasons, corresponds with increasing trends of surface air temperature [19]. This may suggest that the changing ratio of convective and stratiform precipitation is related to climate change and may continue (with increasing temperature) in future. However, our results show that this does not necessarily mean more heavy convective precipitation, because intensity of precipitation depends on a number of factors such as atmospheric humidity and stability, CAPE, and wind shear (e.g., [37]).

The trends of total precipitation are predominantly increasing in all seasons except winter (and 6-hour maxima in spring). The overall tendency to prevailing positive trends agrees with Kyselý [3] who examined trends in characteristics of mean and heavy (total) precipitation in the Czech Republic over 1961-2005 and reported predominantly increasing trends in all seasons except spring. The differences are related to different studied periods, different sets of stations, and the fact that trend estimates may be strongly influenced by values at the beginning and the end of time series. However, our results also show that the overall tendency to rising trends in precipitation characteristics does not depend substantially on the time window.

A distinct differentiation in the predominant trend directions of convective, stratiform, and total precipitation emerges when comparing the western (with stronger Atlantic influence) and the eastern (with stronger Mediterranean and continental influence) parts of the Czech Republic. A tendency to more pronounced trends in convective (stratiform) precipitation in the west (east) may be related to changes of large-scale circulation influencing differently precipitation over these two regions of central Europe; however, the links between large-scale circulation and precipitation are weakest in the convective season (cf. [38]). Increasing trends of stratiform precipitation in autumn in the eastern part of the country may be due to enhanced occurrence of cyclones of the Mediterranean origin (typically associated with widespread and heavy stratiform rainfall). Detailed study of the links between precipitation changes and the large-scale circulation deserves further investigation.

Similar analyses for other parts of Europe are needed in order to reveal whether the reported differences (in trends of convective/stratiform precipitation and mean/extreme characteristics) and the cutoff between the western and eastern parts of the examined area are related to larger-scale patterns over Europe. Such studies should be straightforward because the necessary data (SYNOP reports) are available, and the proposed algorithm [19] is universal and does not involve any "local" settings.

\section{Conclusions}

Using the recently proposed algorithm for disaggregating precipitation into predominantly convective and stratiform [19], we analysed trends in characteristics of convective and 

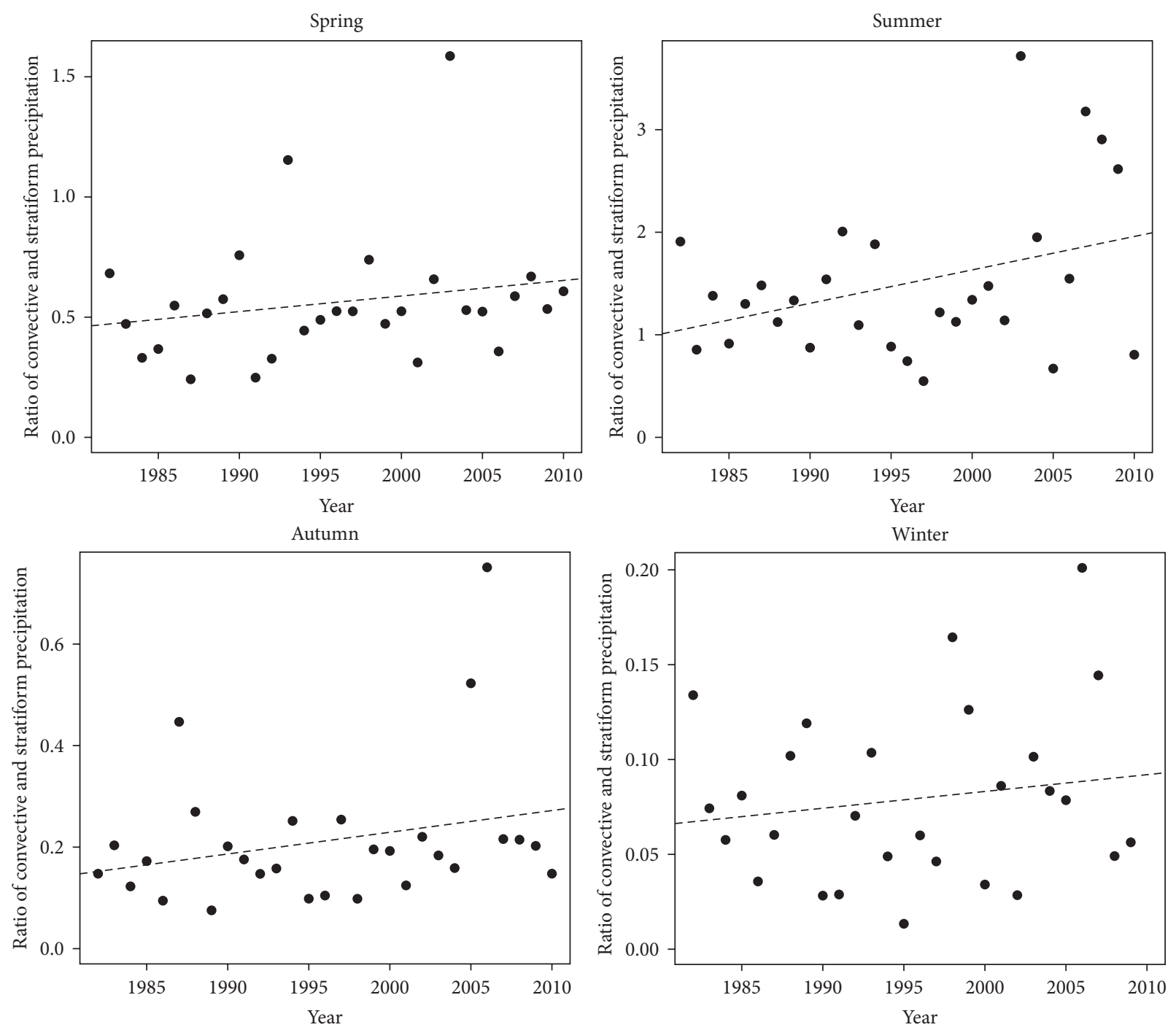

FIGURE 6: Ratio of convective and stratiform precipitation (averages over 11 stations in the Czech Republic) and trend estimated by the linear regression.

stratiform precipitation and their influence on trends of total precipitation at weather stations in the Czech Republic over 1982-2010. The trend analysis was based on the least-squares regression and the Sen's estimator of slope but the results depend little on the method used.

The main findings are as follows.

(i) Spatially averaged trends in convective precipitation are increasing and statistically significant for precipitation amounts and the number of wet days in all seasons except for winter. The trends of extreme convective precipitation (seasonal maxima) are spatially much more variable and insignificant, but increases tend to prevail as well. The trends in convective precipitation are larger in the western part of the country where Atlantic influences are stronger.

(ii) For characteristics of stratiform precipitation, the trends are usually smaller compared to those of convective precipitation, but increases prevail too. They are significant in autumn, especially for extremes, and larger in the eastern part of the country where Mediterranean cyclones play more important role.

(iii) The trends in convective precipitation tend to be more pronounced at lowland than higher-elevated stations while an opposite pattern prevails for stratiform precipitation. This indicates that the increases in convective precipitation are not related to orographically triggered convection. The largest differences in trend magnitudes of convective and stratiform precipitation between lowlands and highlands occur in spring and summer.

(iv) In spring and summer, when convective precipitation represents an important fraction of the total amounts in central Europe (around 30\% and 50\%, resp., when averaged over the stations under study), the observed increases in total precipitation are mainly due to increases in convective precipitation. In autumn, 
increases in both convective and stratiform precipitation are important and the trends are weakest and least pronounced in winter.

Similar studies on changes in convective and stratiform precipitation for other parts of the world are essentially needed in order to better understand the underlying mechanisms of observed changes in precipitation characteristics. The topic is particularly appealing in the context of climate change, as climate models simulate convective and stratiform precipitation separately through different parameterizations. The projected changes in the two components may be compared with the recently observed trend, which might help understand whether the increasing proportion of convective precipitation is a manifestation of a warming trend or not.

\section{Conflict of Interests}

The authors declare that they have no conflict of interests regarding the publication of this paper.

\section{Acknowledgments}

The authors are grateful for useful discussions and help with preparation of the data to P. Pešice and P. Sedlák, Institute of Atmospheric Physics, Prague. The study was supported by the European Social Fund and the Ministry of Education of the Czech Republic under Project no. CZ.1.07/2.3.00/20.0086.

\section{References}

[1] A. Moberg, P. D. Jones, D. Lister et al., "Indices for daily temperature and precipitation extremes in Europe analyzed for the period 1901-2000," Journal of Geophysical Research D, vol. 111, no. 22, Article ID D22106, 2006.

[2] D. Maraun, T. J. Osborn, and N. P. Gillett, "United Kingdom daily precipitation intensity: improved early data, error estimates and an update from 2000 to 2006," International Journal of Climatology, vol. 28, no. 6, pp. 833-842, 2008.

[3] J. Kyselý, "Trends in heavy precipitation in the Czech Republic over 1961-2005," International Journal of Climatology, vol. 29, no. 12, pp. 1745-1758, 2009.

[4] A. C. Costa and A. Soares, "Trends in extreme precipitation indices derived from a daily rainfall database for the South of Portugal," International Journal of Climatology, vol. 29, no. 13, pp. 1956-1975, 2009.

[5] V. Pavan, R. Tomozeiu, C. Cacciamani, and M. di Lorenzo, "Daily precipitation observations over Emilia-Romagna: mean values and extremes," International Journal of Climatology, vol. 28, no. 15, pp. 2065-2079, 2008.

[6] J. M. Hidalgo-Muñoz, D. Argüeso, S. R. Gámiz-Fortis, M. J. Esteban-Parra, and Y. Castro-Díez, "Trends of extreme precipitation and associated synoptic patterns over the southern Iberian Peninsula," Journal of Hydrology, vol. 409, no. 1-2, pp. 497-511, 2011.

[7] F. S. Rodrigo and R. M. Trigo, "Trends in daily rainfall in the Iberian Peninsula from 1951 to 2002," International Journal of Climatology, vol. 27, no. 4, pp. 513-529, 2007.

[8] Y. Hundecha and A. Bárdossy, "Trends in daily precipitation and temperature extremes across western Germany in the second half of the 20th century," International Journal of Climatology, vol. 25, no. 9, pp. 1189-1202, 2005.

[9] A. Moberg and P. D. Jones, "Trends in indices for extremes in daily temperature and precipitation in central and western Europe, 1901-99," International Journal of Climatology, vol. 25, no. 9, pp. 1149-1171, 2005.

[10] S. Hänsel, S. Petzold, and J. Matschullat, "Precipitation trend analysis for central eastern Germany 1851-2006," in Bioclimatology and Natural Hazards, K. Strelcová, C. Matyas, A. Kleidon et al., Eds., pp. 29-38, Springer, Amsterdam, The Netherlands, 2009.

[11] E. Łupikasza, "Spatial and temporal variability of extreme precipitation in poland in the period 1951-2006," International Journal of Climatology, vol. 30, no. 7, pp. 991-1007, 2010.

[12] E. B. Łupikasza, S. Hänsel, and J. Matschullat, "Regional and seasonal variability of extreme precipitation trends in southern Poland and central-eastern Germany 1951-2006," International Journal of Climatology, vol. 31, no. 15, pp. 2249-2271, 2011.

[13] F. S. Rodrigo, "Changes in the probability of extreme daily precipitation observed from 1951 to 2002 in the Iberian Peninsula," International Journal of Climatology, vol. 30, no. 10, pp. 1512$1525,2010$.

[14] S. Trömel and C. D. Schönwiese, "Probability change of extreme precipitation observed from 1901 to 2000 in Germany," Theoretical and Applied Climatology, vol. 87, no. 1-4, pp. 29-39, 2007.

[15] H. Y. Lam, L. Luini, J. Din, C. Capsoni, and A. D. Panagopoulos, "Stratiform and convective rain discrimination for equatorial region," in Proceedings of the 8th IEEE Student Conference on Research and Development-Engineering: Innovation and Beyond (SCOReD '10), pp. 112-116, Putrajaya, Malaysia, December 2010.

[16] Z. Sokol and V. Bližňák, "Areal distribution and precipitationaltitude relationship of heavy short-term precipitation in the Czech Republic in the warm part of the year," Atmospheric Research, vol. 94, no. 4, pp. 652-662, 2009.

[17] R. Yu, W. Yuan, J. Li, and Y. Fu, "Diurnal phase of latenight against late-afternoon of stratiform and convective precipitation in summer southern contiguous China," Climate Dynamics, vol. 35, no. 4, pp. 567-576, 2010.

[18] A. M. Ruiz-Leo, E. Hernández, S. Queralt, and G. Maqueda, "Convective and stratiform precipitation trends in the Spanish Mediterranean coast," Atmospheric Research, vol. 119, pp. 46-55, 2013.

[19] Z. Rulfová and J. Kyselý, "Disaggregating convective and stratiform precipitation from station weather data," Atmospheric Research, vol. 134, pp. 100-115, 2013.

[20] R. Tolasz, T. Míková, and A. Valeriánová, Climatic Atlas of Czechia, Czech Hydrometeorological Institute and Palacký University, Prague, Czech Republic, 2007.

[21] J. Štekl, R. Brázdil, V. Kakos, J. Jež, R. Tolasz, and Z. Sokol, Extreme Daily Precipitation on the Territory of the Czech Republic in the Period 1879-2000 and Their Synoptic Causes, Czech Hydrometeorological Institute, Prague, Czech Republic, 2001.

[22] D. S. Wilks, Statistical Methods in the Atmospheric Science, Academic press, New York, NY, USA, 1995.

[23] B. Efron and R. J. Tibshirani, An Introduction to the Bootstrap, vol. 57 of Monographs on Statistics and Applied Probability, Chapman and Hall, London, UK, 1993.

[24] A. C. Davison and D. V. Hinkley, Bootstrap Methods and Their Applications, vol. 1 of Cambridge Series in Statistical 
and Probabilistic Mathematics, Cambridge University Press, Cambridge, UK, 2003.

[25] P. K. Sen, "Estimates of the regression coefficient based on Kendall's tau," Journal of the American Statistical Association, vol. 63, no. 324, pp. 1379-1389, 1968.

[26] H. B. Mann, "Nonparametric tests against trend," Econometrica, vol. 13, no. 3, pp. 245-259, 1945.

[27] M. Kendall, Multivariate Analysis, Charles Griffin \& Company, London, UK, 1975.

[28] R. Huth and L. Pokorná, "Parametric versus non-parametric estimates of climatic trends," Theoretical and Applied Climatology, vol. 77, no. 1-2, pp. 107-112, 2004.

[29] E. Black, M. Blackburn, G. Harrison, B. Hoskins, and J. Methven, "Factors contributing to the summer 2003 European heatwave," Weather, vol. 59, no. 8, pp. 217-223, 2004.

[30] A. H. Fink, T. Brücher, A. Krüger, G. C. Leckebusch, J. G. Pinto, and U. Ulbrich, "The 2003 European summer heatwaves and drought-synoptic diagnosis and impacts," Weather, vol. 59, no. 8, pp. 209-216, 2004.

[31] E. M. Fischer, S. I. Seneviratne, D. Lüthi, and C. Schär, "Contribution of land-atmosphere coupling to recent European summer heat waves," Geophysical Research Letters, vol. 34, no. 6, pp. 1-6, 2007.

[32] J. Kyselý, "Recent severe heat waves in central Europe: how to view them in a long-term prospect?" International Journal of Climatology, vol. 30, no. 1, pp. 89-109, 2010.

[33] Z. Bielec, "Long-term variability of thunderstorms and thunderstorm precipitation occurrence in Cracow, Poland, in the period 1896-1995," Atmospheric Research, vol. 56, no. 1-4, pp. 161-170, 2001.

[34] Z. Bielec-Bąkowska, "Long-term variability of thunderstorm occurrence in Poland in the 20th century," Atmospheric Research, vol. 67-68, pp. 35-52, 2003.

[35] J. O. Haerter and P. Berg, "Unexpected rise in extreme precipitation caused by a shift in rain type?" Nature Geoscience, vol. 2, no. 6, pp. 372-373, 2009.

[36] P. Berg, C. Moseley, and J. O. Haerter, "Strong increase in convective precipitation in response to higher temperature," Nature Geoscience, vol. 6, no. 3, pp. 181-185, 2013.

[37] R. A. Houze Jr., Cloud Dynamics, Academic Press, San Diego, Calif, USA, 1993.

[38] R. Huth and J. Kyselý, "Constructing site-specific climate change scenarios on a monthly scale using statistical downscaling," Theoretical and Applied Climatology, vol. 66, no. 1-2, pp. 13-27, 2000. 

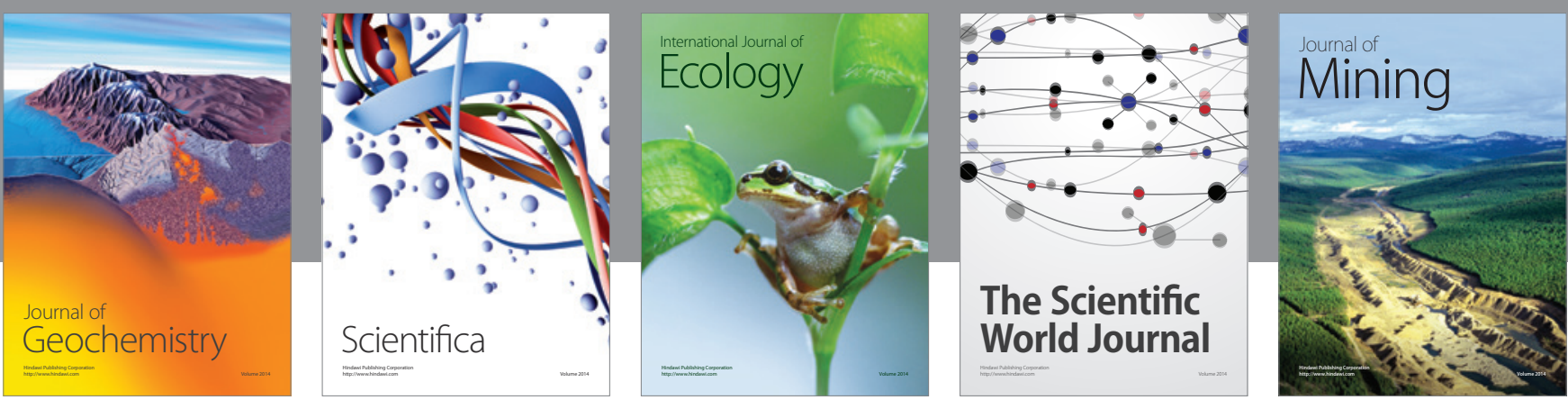

The Scientific World Journal
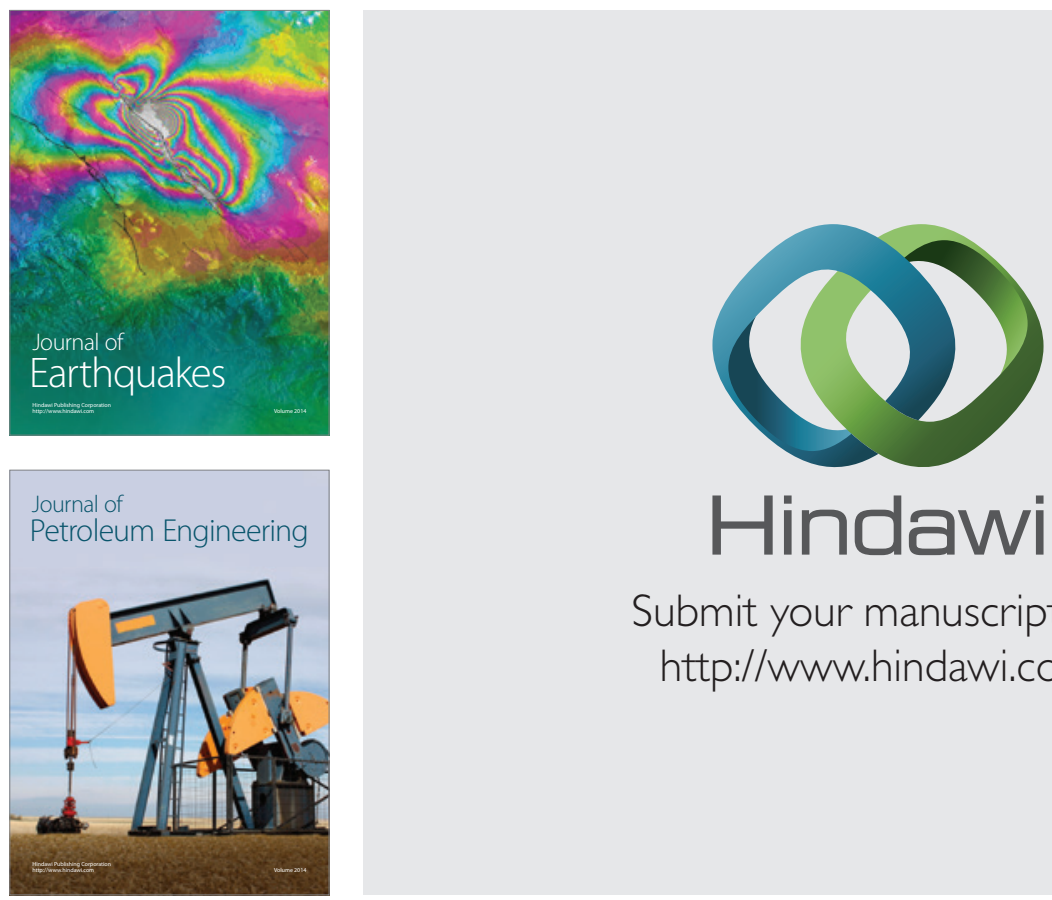

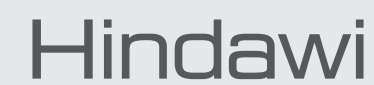

Submit your manuscripts at

http://www.hindawi.com
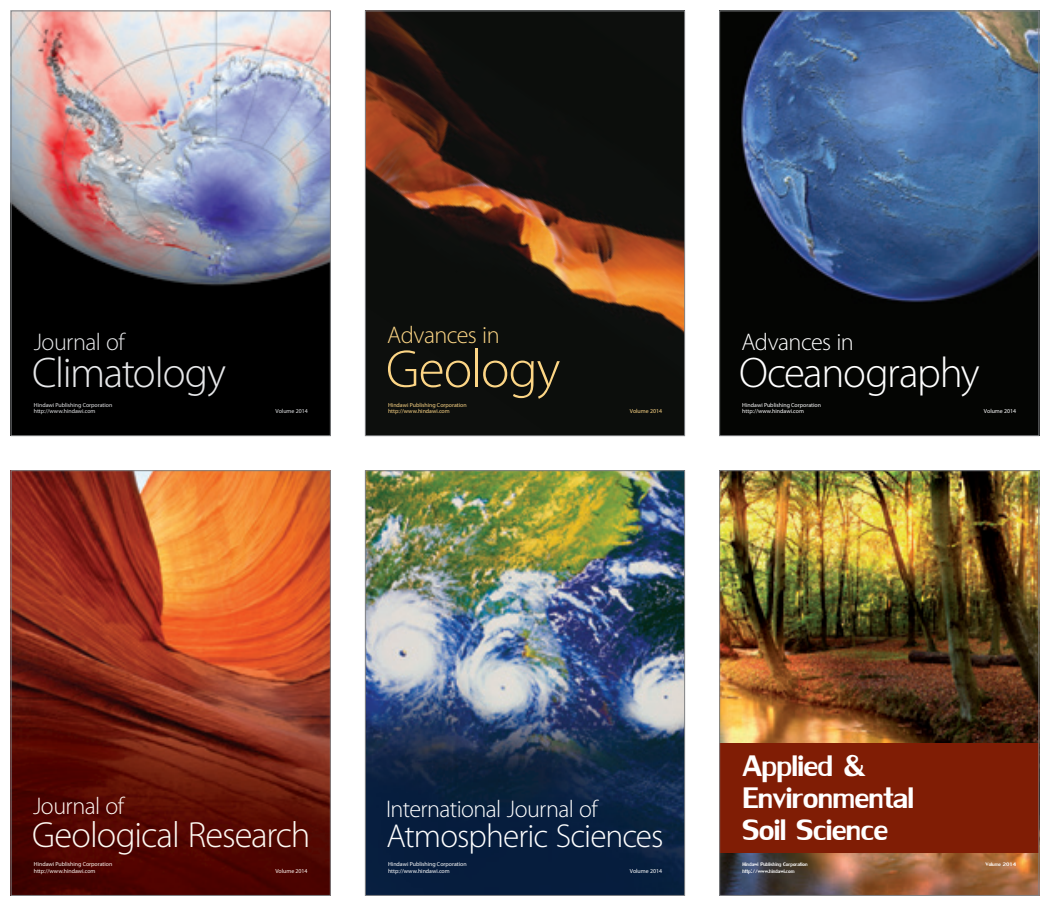
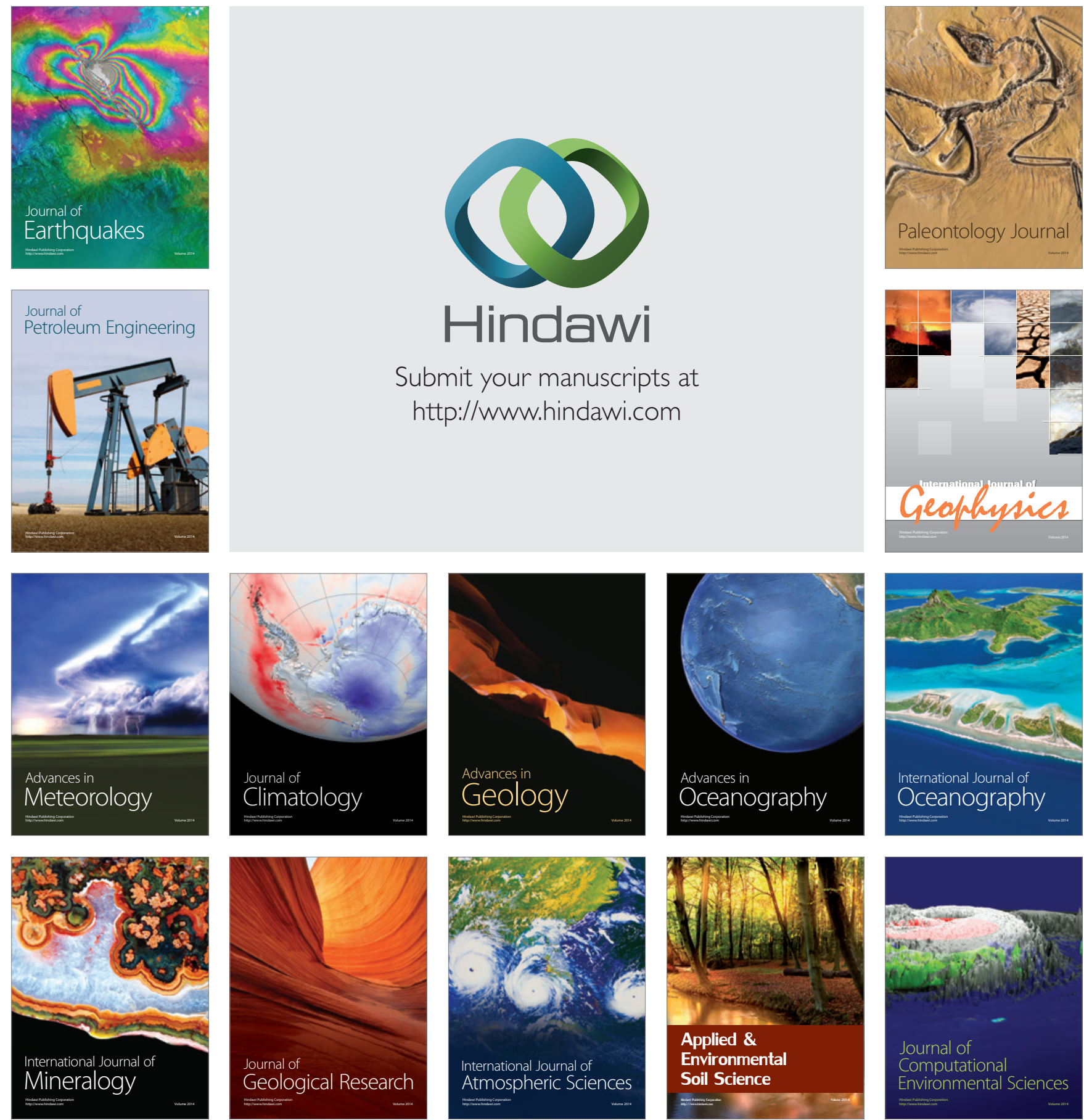